\title{
Transonic Unsteady Aerodynamic and Aeroelastic Calculations About Airfoils and Wings
}

\section{Peter M. Goorjian and Guru P. Guruswamy}

\author{
(NASA-TM-89417) TRANSCNIC UNSTEADY \\ AERODYNAMIC AND AEROELASTIC CALCULATIONS \\ AEOUT AIBFCILS ANC WINGS (NASA) 9 p \\ CSCL 01A Unclas \\ G $3 / 02 \quad 43922$
}

N87-16800

January 1987 
NASA Technical Memorandum 89417

\section{Transonic Unsteady Aerodynamic and Aeroelastic Calculations About Airfoils and Wings}

Peter M. Goorjian, Ames Research Center, Moffett Field, California

Guru P. Guruswamy, Sterling Federal Systems Inc., Palo Alto, California

January 1987

\section{N/Sก}

National Aeronautics and

Space Administration

Ames Research Center

Moffett Field, California 94035 


\title{
TRANSONIC UNSTEADY AERODYNAMIC AND AEROELASTIC CALCULATIONS ABOUT AIRFOILS AND WINGS
}

\author{
Peter M. Goorjian \\ NASA Ames Research Center, Moffett Field, CA 94035 USA \\ and \\ Guru P. Guruswamy \\ Sterling Federal Systems Inc., Palo Alto, CA USA
}

\section{INTRODUCTION}

This article will survey some of the research in the area of computational unsteady transonic flows about airfolls and wings, including aeroelastic effects. $[1,2]$ In the last decade, there have been extensive developments in computational methods in response to the need for computer codes with which to study fundamental aerodynamic and aeroelastic problems in the critical transonic regime. For example, large commercial aircraft cruise most effectively in the transonic flight regime and computational fluid dynamics (CFD) provides a new tool, which can be used in combination with test facilities to reduce the costs, time, and risks of aircraft development. One of the major uses of unsteady transonic aerodynamics is in the flutter analysis of supercritical wings. Experiments have shown that dips occur at transonic Mach numbers in the flutter boundaries for wings and such dips are especially severe for supercritical wings. This phenomenon is attributable to the motion of shock waves on the wings. The proper modeling of the physics of such moving shock waves requires that the CFD methods solve nonlinear partial differential equations for regions of mixed subsonic and supersonic flow. Currently, the most advanced codes use potential equations for modeling the flow; such codes are being used for generic research in aeroelasticity. More advanced codes are under development that use the Euler and Navier-Stokes equations; such codes can model vortices in addition to the shock waves.

In this article, first a result [2] will be shown of transonic flow with moving shock waves over a pitching airfoil. Then results 
will be presented for flow over (1) a transport wing, [2] including aeroelastic calculations and (2) a low-aspect-ratio wing. [3] in all cases, comparisons with experimental data will be made.

\section{TRANSONIC FLOW OVER AIRFOILS}

The development of algorithms and codes for simulating unsteady transonic flows by solving the unsteady transonic small disturbance potential equation was started at NASA Ames Research Center by Ballhaus and Lomax. Initially a code, called LTRAN2, was developed[4] for a low frequency approximation to the governing equation. Later the code was generalized to account for all frequencies and was called ATRAN2. The algorithm used in the code is an alternating-direction, implicit (ADI), finite-difference scheme. It is conservative and time-accurate so that shock wave motions are modeled correctly. There have been many improvements to the code, including improvements in: (1) accuracy, such as the use of second-order differencing; (2) stability, such as the use of monotone schemes; and (3) capability, such as the inclusion of viscous modeling and the capability to model wind tunnel walls and supersonic free streams. See refs. 1-2 for details.

In Fig. 1, a calculation ${ }^{[2]}$ is shown for the ATRAN2 code. The results are for transonic flow over a pitching NACA-0012 airfoil. The calculations show the effects of including viscous modeling and are compared with experimental data. Eigure 2 shows results over a cycle of motion, during which the shock wave appears, grows quite strong, and then disappears. This case demonstrates the necessity of solving a nonlinear governing equation in a time accurate manner in order to correctly account for the shock wave behavior.

\section{TRANSONIC FLOW OVER WINGS}

The two dimensional algorithm has been extended to three dimensions and there have been extensive code developments and computations of transonic flow over wings. $[1,2,3]$

The first case shown here is for flow over a transport wing. [2] Figure 3 shows the model tested in Japan. Figure 4 shows results for steady flow (using the code XTRAN3S), which show the presence of a 
strong shock wave. Figure 5 shows results for unsteady aerodynamics with comparisons that show the inadequacy of using linear equation methods (doublet lattice) at transonic speeds. Finally, Fig. 6 shows results for the flutter boundary in the transonic-dip, Mach-number range.

The second case shows results for flow over the F-5 wing. For this wing, algorithm developments were needed for an adequate computational grid.[3] Fig. 7 shows the model and Eig. 8 shows the pitching motion. Finally, Fig. 9 shows the comparison of the computed results (using the code ATRAN3S), with experimental data of the unsteady pressure coefficients on the upper surface. The agreement with experiment in both the real and the imaginary components near the midchord region of the wing shows that the motion of the shock wave, which occurs there, is correctly simulated.

\section{REFERENCES}

[1] Goorjian, P. M.:"Computations of Unsteady Transonic Elows," Chapter 8 in Advances in Computational Transonics; Vol. IV in the series: Recent Advances in Numerical Methods in Fluids, Ed. W. G. HABASHI, Pineridge Press Ltd., Swansea, U.K., 1985.

[2] Goorjian, P. M. and Guruswamy, G. P., "Unsteady Transonic Aerodynamic and Aeroelastic Calculations about Airfoils and Wings," AGARD Specialists Meeting on Transonic Unsteady Aerodynamics and Its Aeroelastic Applications, Toulouse, France, AGARD Conference. Proceedings No. 374, Paper No. 15, September 1984.

[3] Guruswamy, P. and Goorjian, P. M., "Efficient Algorithm for Unsteady Transonic Aerodynamics of Low-Aspect Ratio Wings," J. Alrcraft, March, 1985, p. 193. Also AIAA Paper 84-0872-CP, 25th AIAA Structural Dynamics Conf., Palm Springs, May 1984.

[4] Ballhaus, , W. F., and GoorJian, P. M.: Implicit Finite-Difference Computations of Unsteady Transonic Flows About Airfoils, Including the Treatment of Irregular Shock-Wave Motions. AIAA Paper No. 77-205, AIAA 15th Aerospace Sciences Meeting, Los Angeles, Jan. 1977, AIAA Journal, Vol. 15, No. 12, Dec. 1977 , pp. 1728-1735. 

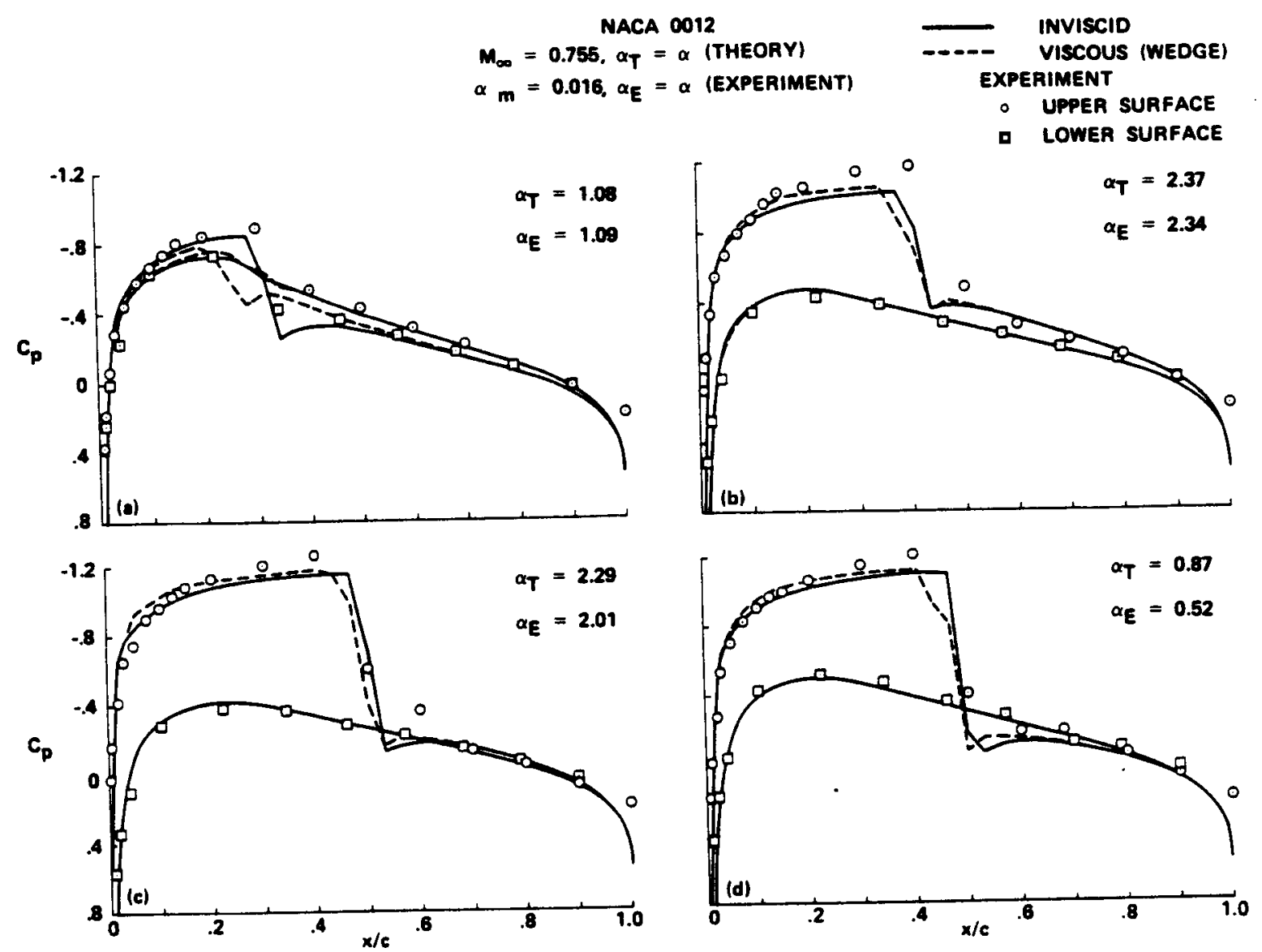

Fig. 1 Unsteady pressure coefficients for a NACA 0012 airfoil, $M=0.755, k=0.1628$, mean angle is 0.016 deg, pitching angle is $2.51 \mathrm{deg}$.

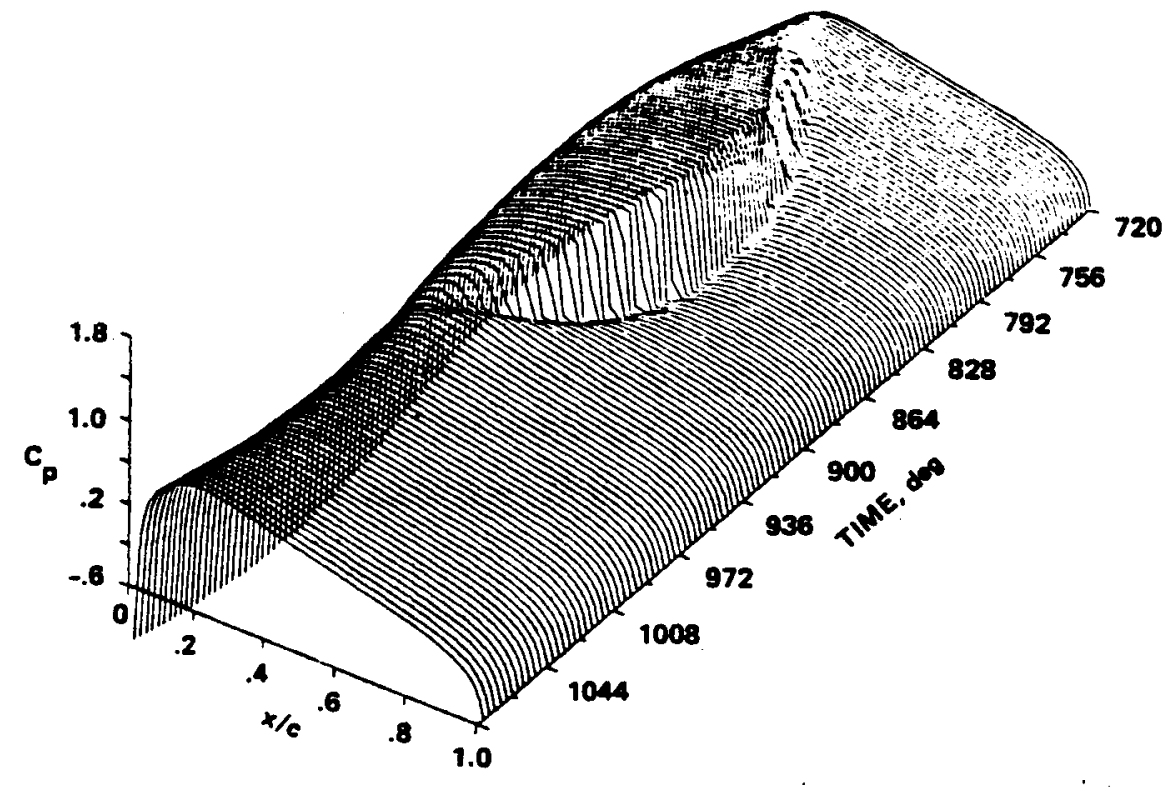

Fig. 2 Time history of upper surface pressure coefficients, NACA $0012, M=0.755, k=0.1628$. 


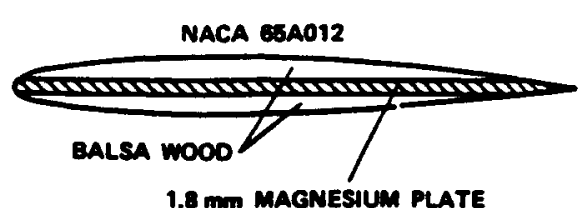

FLUTTER ANALYSIS OF JAPANESE TAANSPORT WING

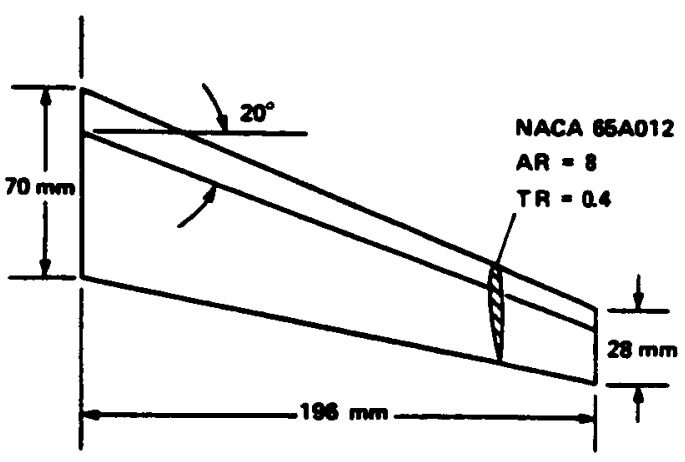

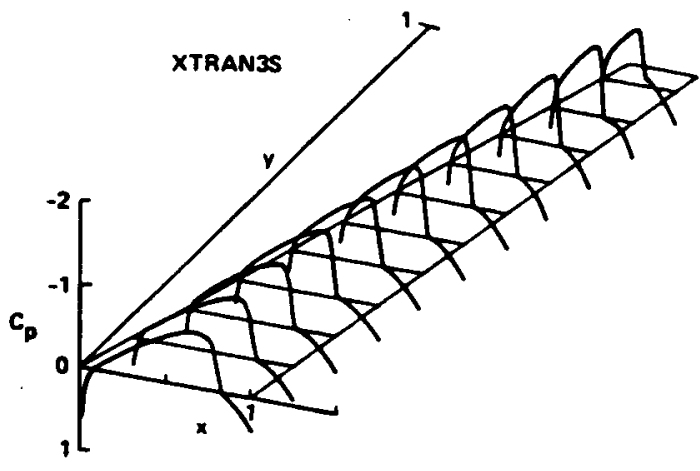

Fig. 4 Steady state initial conditions for the transport wing, $M=0.85$.

Eig. 3 Code correlation model of Japanese transport wing.

FIRST BENOING MODE DOUBLET LATTICE XTRAN3S

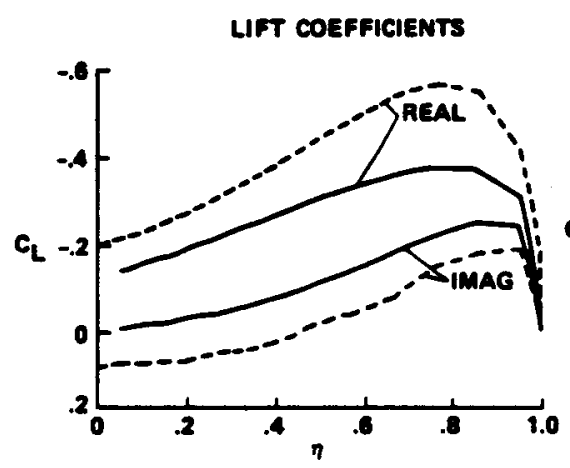

LEAOING EDGE MOMENT COEFFICIENTS

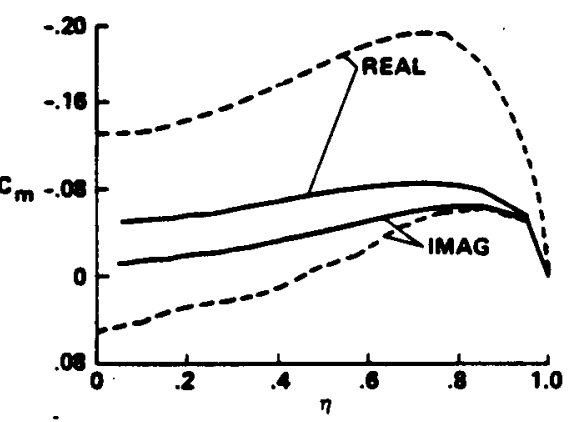

Fig. 5 Modal aerodynamics for the transport wing, $M=0.85$, $\mathbf{k}=0.121$.

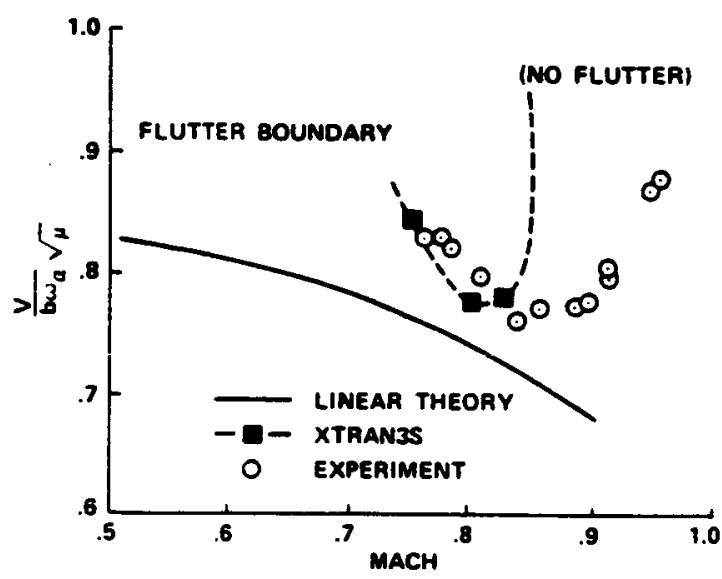

Fig. 6 Flutter boundaries, computations and experiment. 


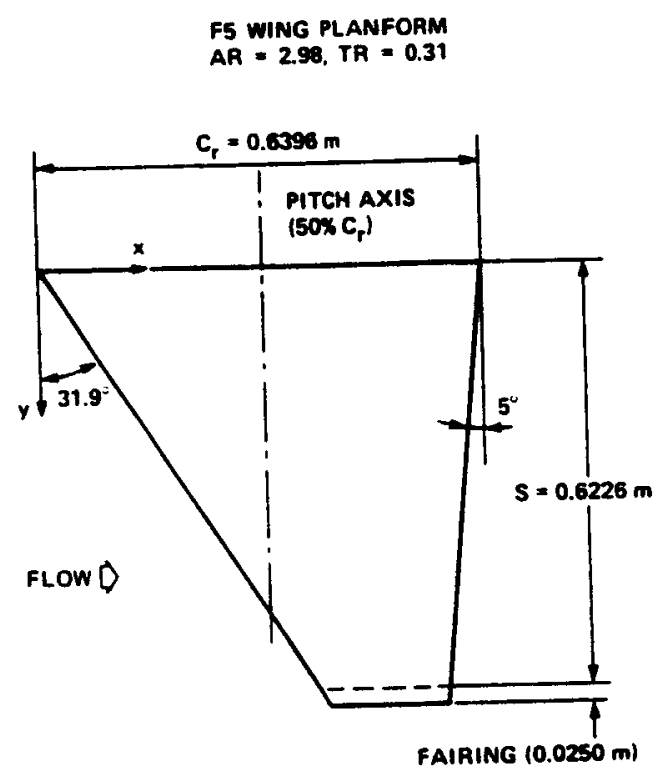

Fig. 7 Dimensions of the F-5 wing.
FS WING: $A R=2.99$, TR $=0.31$, LE SWEEP $=32^{\circ}$

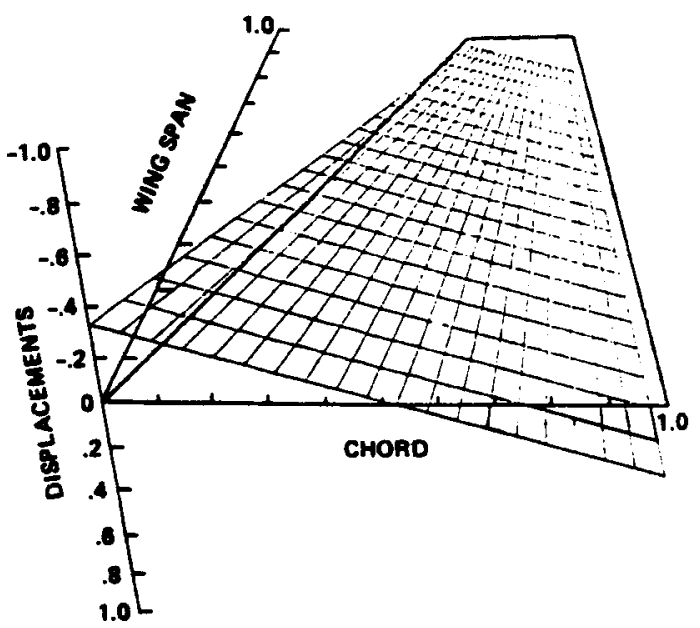

Fig. 8 Unsteady modal motion of the E-5 wing.

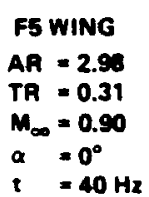

$t=40 \mathrm{~Hz}$

UNSTEADY UPPER SURFACE $\mathrm{C}$ \begin{tabular}{l|l} 
- REAL & AMTAANBS
\end{tabular}

口 REAL

$\triangle$ IMAGINARY

ATRAN3S

NLR EXPERIMENT

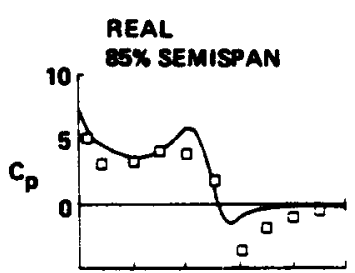

IMAGINARY

ES\% SEMISPAN
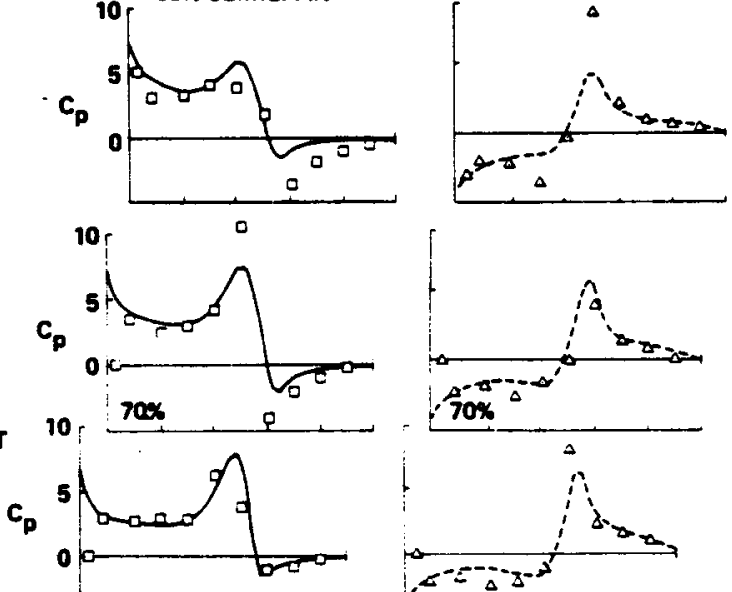$$
\text { 10. } 50 x
$$

$c_{p}$
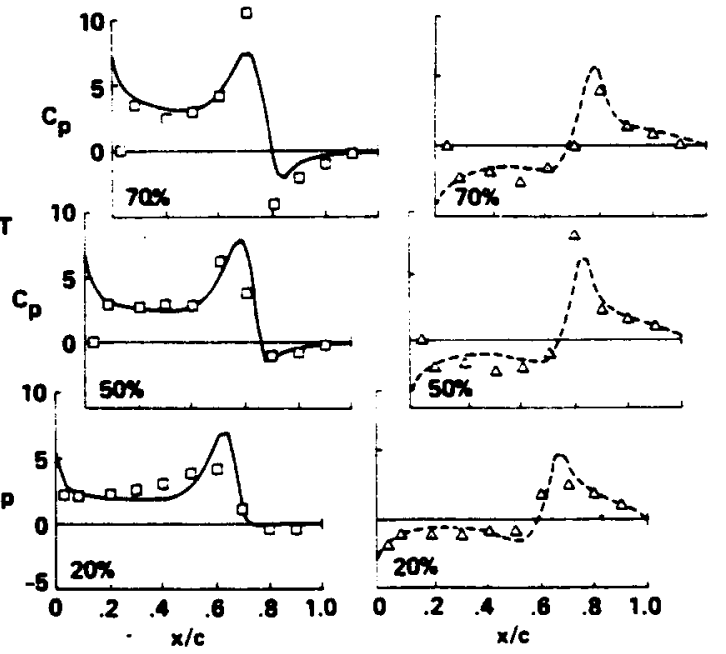

Fig. 9 Comparisons of unsteady pressure coefficients, computations and experiment. 


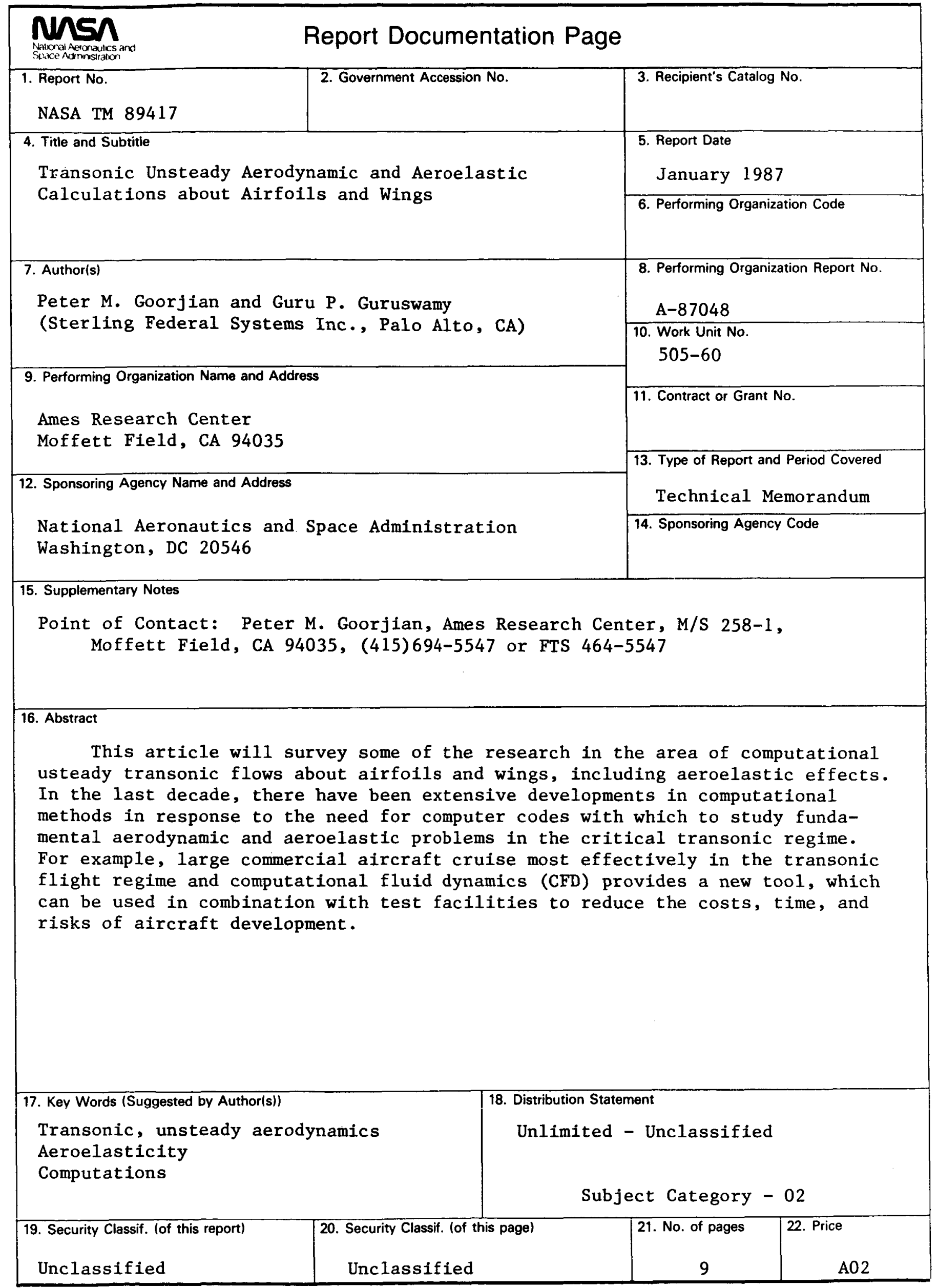

